\title{
An Experimental Investigation of Transpiration Cooling. Part I: Application of an Infrared Measurement Technique
}

\author{
J. H. Wang \\ 13th Department, University of Science and Technology of China, Hefei, People's Republic of China
}

\section{J. Messner and H. Stetter}

Institut für Thermische Strömungsmaschinen und Maschinenlaboratorium, University of Stuttgart, Stuttgart, Germany

This study was an investigation into the application of the infrared thermal imaging technique (IRTIT) to evaluate transpiration cooling performance through a porous wall. Two typical infrared thermograph systems, the AGA 782 short-wavelength system and the VARIOSCAN 3021 long-wavelength system, were employed to demonstrate the availability of the IRTIT measurement. In comparison with general infrared apparent temperature measurement, several factors that influence measurement accuracy need to be addressed in the application of the IRTIT in the region of transpiration cooling on the porous surfaces of turbine components. In this article, the influence of these factors on measurement accuracy is discussed, the corresponding calibration methods of the two infrared systems are described, and the ambient conditions and stability of the measurement are analyzed. A porous circular tube was used as a specimen. The tube consisted of sintered chromium-nickel steel with a porosity of $21 \%$. The experiment was carried out in the hotgas wind tunnel at the Institute of Thermal Turbomachinery at the University of Stuttgart, Stuttgart, Germany.

Keywords Experimental technique; Infrared measurement; Transpiration cooling

Received 1 April 2002; accepted 1 April 2002.

The initial study (JHW) was supported by the China Scholarship Council.

The authors are grateful to the colleagues of Infrarot Technik $\mathrm{GmbH}$ for their helpful suggestions and mechanics and to Mr. Maegel, Mr. Brausewetter, and Mr. Krinn for their assistance in this experimental work.

Address correspondence to Dr. Joachim Messner, Universitat Stuttgart-ITSM, Pfaffenwaldring 6, Stuttgart, D 70569, Germany. E-mail: messner@itsm.uni-stuttgart.de
An increase in the thermal efficiency and specific power of gas turbine systems can be achieved through higher turbine inlet temperature, but as the inlet temperature increases, material limits, such as the creep and failure of turbine components, are of great concern. Thus, it is very important to improve cooling methods.

In the development of cooling methods, experiments are important. The measurement techniques used in film-cooling investigations can be classified into two groups. In the first group, coolant is injected at a temperature different from mainstream temperature, and surface temperature is measured directly. For example, Nirmalan and colleagues (1998) used a series of thermocouples installed in grooves on the exterior surface of the test vane, and Ekkad and colleagues (1997a, 1997b) employed the transient liquid crystal imaging method. In the second group, tracer gas is fed into the mainstream field, the concentration of tracer gas is measured, and the cooling effect is indirectly obtained through the analogy of heat and mass transfer; the ammonia-diazo method developed by Friedrichs and colleagues (1997) and the widely used naphthalene sublimation technique are two successful instances. But these techniques are not suitable for porous-surface cooling because various coating techniques and a large number of thermocouples will lead to a change in the permeability of the porous wall. Therefore, the infrared thermal imaging technique (IRTIT) is an important method for measuring the transpiration cooling on a porous surface.

Using the IRTIT to survey the effect of turbine components is not a new idea. In recent years, the application of the IRTIT in various investigational aspects has been reported by a number of researchers (Boyle et al., 2001; Martiny et al., 1995; Sargent et al., 1998; Scherer et al., 1991; Schmidt et al., 1996; Sweeney and Rhodes, 2000). In comparison with these measurements, the application of the IRTIT in transpiration cooling involves several new factors. This study attempts to provide a comprehensive 
reference for the application of the IRTIT to estimate transpiration cooling performance for the researchers of transpiration cooling techniques and for subsequent research work, which is presented in Part II.

\section{EXPERIMENTAL SETUP}

\section{Wind Tunnel}

The hot-gas wind tunnel in the Institute of Thermal Turbomachinery at the University of Stuttgart is shown schematically in Figure 1. The calibration tests presented in Part I and the cooling performance comparison experiments presented in Part II of this article were carried out in this wind tunnel. Atmospheric air was injected into the wind tunnel by an air compressor. The air was heated by a resistance heater with a power of $200 \mathrm{~kW}$, and the maximum allowable temperature of the wind tunnel was $300^{\circ} \mathrm{C}$. The test section following a contraction section (12:1 area ratio) was $112 \mathrm{~mm}$ across $\times 52 \mathrm{~mm}$ high $\times 1400 \mathrm{~mm}$ long. The turbulence in the test section was reduced by two fine filters and a honeycomb upstream of the contraction section. The free-stream temperature at the inlet of the test section could be kept constant by a digital control system (the maximal tolerance of a given level being $\pm 1 \mathrm{~K}$ ). Two different cooling media could be supplied-a gaseous coolant at atmospheric temperature from a vessel with a pressure of 10 bar or distilled water from the power plant at the University of Stuttgart. A water pump and a pressure control system were employed to control the water flow rate. A PC-based ac- quisition system was connected with the measurement sensors. The temperature and dynamic pressure distributions across the test section at the inlet and exit of the test section were measured with thermocouples and Prandtl probes. The static pressure distribution along the test section was surveyed by using a pressure scanner. There were three infrared-transmissible windows, each with a screen size of $25 \times 70 \mathrm{~mm}^{2}$ in the test section. Through the three windows, the leading and trailing stagnation regions and the side surface of the specimen could be surveyed.

\section{Porous Specimen and Cooling Configuration}

Circular or semicircular cylinders are often used to simulate the leading region of turbine blades in the investigations of film cooling. For example, Bonnice and L'Ecuyer (1983) used a circular cylinder with several rows of span-wise injection holes to study the cooling nature of leading stagnation region; Karni and Goldstein (1990) employed a circular cylinder with one row of inclined holes to research the effect of surface injection on local mass and heat transfer; Mehendale and Han (1992) adopted a blunt body with a circular leading edge to evaluate the effect of free-stream turbulence on the film-cooling effectiveness and surface heat transfer coefficient; and Ekkad and colleagues (1998) used a circular cylinder to investigate the influence of free-stream turbulence and coolant density on film cooling.

In this study, a further attempt was made to simulate the transpiration cooling performance in the leading, side, and trailing regions of a turbine blade, using a tube as a specimen. The tube

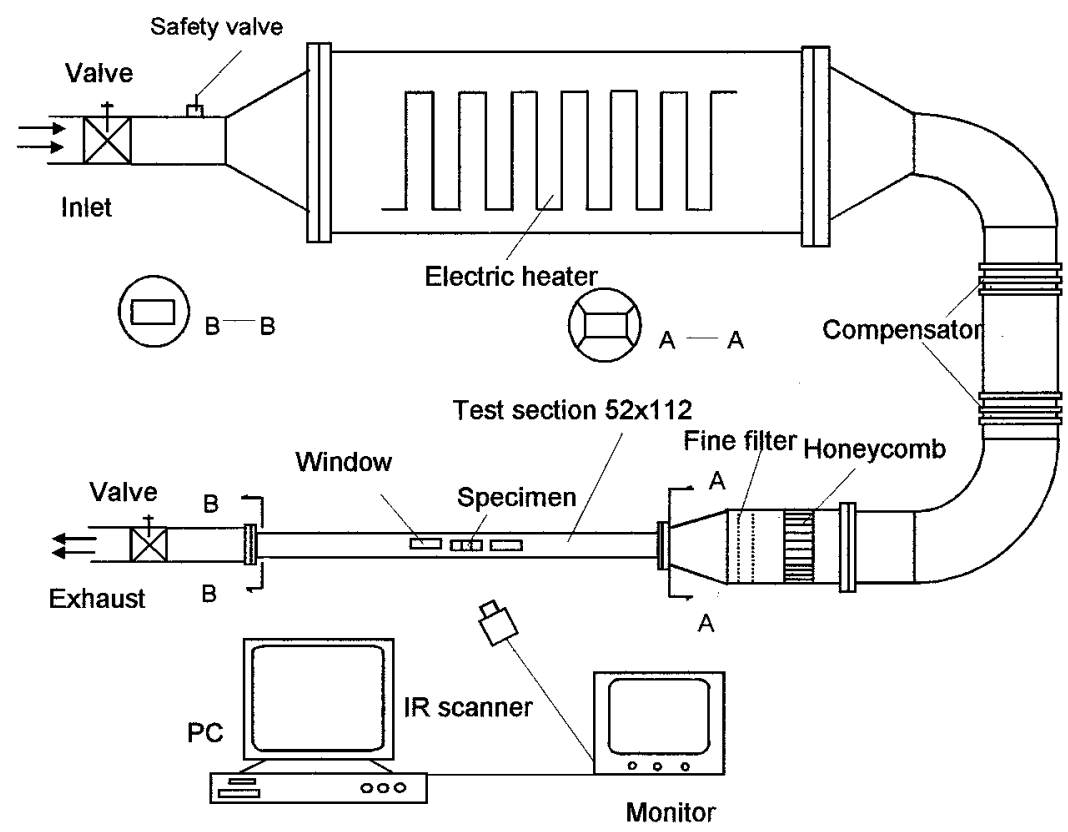

FIGURE 1

Schematic of hot-gas wind tunnel. 


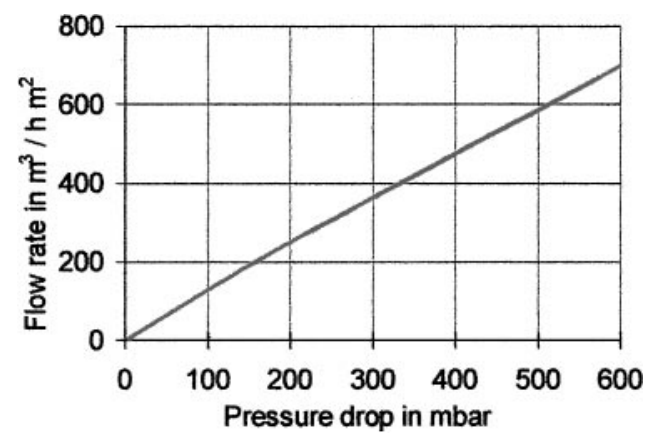

FIGURE 2

Air permeability of porous material.

had a height of $52 \mathrm{~mm}$, a diameter of $36.5 \mathrm{~mm}$, and a thickness of $3.5 \mathrm{~mm}$. The smallest, the most effective, and the largest pore diameters of the porous material were $4 \mu \mathrm{m}, 6 \mu \mathrm{m}$, and $11 \mu \mathrm{m}$, respectively. Figure 2 illustrates the characteristic line of pure-air permeability. Figure 3 shows the cooling configuration. A core with four coolant chambers was installed into the porous tube. The chambers stood at the leading line, at \pm 45 degrees from the leading line and trailing line. Several closed sealings were used to control the coolant injected to flow into the desired regions. If the chambers at the leading and trailing lines were supplied with coolant, the nature of the cooling in the corresponding regions was similar to that of the leading and trailing regions of a turbine blade; when the chambers at \pm 45 degrees from the leading line were injected, the cooling effect was similar to that of the curvature of the suction surface of a turbine blade.

\section{Infrared Scanner}

AGA 782 is a short-wavelength infrared system. Its receiving wavelength ranges from $3 \mu \mathrm{m}$ to $5.6 \mu \mathrm{m}$, with a $0^{\circ} \mathrm{C}$ to $1000^{\circ} \mathrm{C}$ measurement range and an image array of $127 \times 127$. VARIOSCAN 3021 is a new product with a long-wavelength detector ranging from $8 \mu \mathrm{m}$ to $12 \mu \mathrm{m}$. Its measurement range, as provided by the manufacturer (InfraTec $\mathrm{GmbH}$ ), is $-40^{\circ} \mathrm{C}$ to $1200^{\circ} \mathrm{C}$, with an image array of $360 \times 240$. AGA 782 system

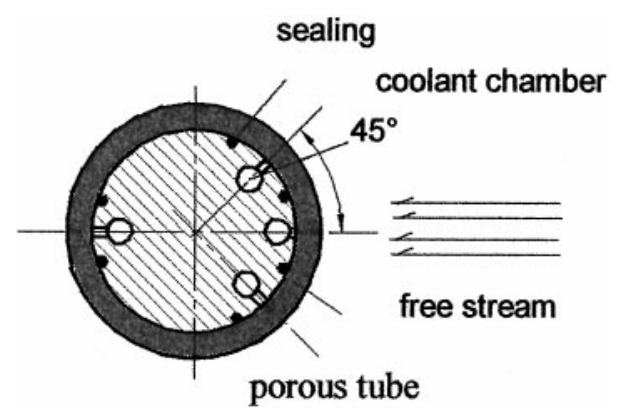

FIGURE 3

Cross-section of the specimen. can provide a digital block file of pixel-by-pixel gray-scale levels, namely video signal, whereas VARIOSCAN 3021 directly provides output of temperature distribution. The benefits of the latter are digital focus and higher geometrical and thermal resolution. The detectors of the two systems have to be cooled with liquid nitrogen.

\section{FACTORS INFLUENCING OF MEASUREMENT}

The infrared measurement technique has two advantages over traditional temperature measurement methods. First, a twodimensional infrared thermal image can provide complete information regarding temperature and space. The second benefit is that it is a nonintrusive measurement. But the application of the IRTIT in the transpiration cooling of turbine component concerns some new factors.

\section{Material of Infrared Transmissible Windows}

In general, most cooling experiments involving gas turbine components are carried out in hot-gas wind tunnels. Thus, the IRTIT requires an infrared-transmissible window in the test section at least. The following materials were used as the infraredtransmissible windows:

1. Sapphire; it is one of the hardest materials and can provide good transmission characteristics over the visible and nearinfrared spectrum (wavelengths $300 \mathrm{~nm}$ to $4.5 \mu \mathrm{m}$ ). Its average refractive index is about 1.77. Martiny and colleagues (1995) and Wittig and colleagues (1996) used this material as infrared transmissible windows.

2. Zinc selenide; it can transmit infrared radiation from $500 \mathrm{~nm}$ to $15 \mu \mathrm{m}$. Its average refractive index of 2.4 results in a reflection loss of $17 \%$ per surface. Coating is available to reduce the loss, but the coated windows have to be cooled because the maximum temperatures of coating materials are usually lower than the temperatures of test operation. Sweeney and Rhodes (2000) and Boyle and colleagues (2001) employed coated zinc selenide windows.

3. Calcium fluoride; this crystal provides very good transmission (about 90\%) in the range of $150 \mathrm{~nm}$ to $8 \mu \mathrm{m}$. Its low refractive index of 1.4 eliminates the need for antireflection coating. The view window used by Scherer and colleagues (1991) was made of this material.

These three materials influence measurement data at different levels. Figure 4 illustrates their optical natures; Table 1 compares their mechanical natures. For short-wavelength infrared systems, sapphire is preferable because its mechanical nature is better than that of calcium fluoride, and its optical natures are better than those of zinc selenide. For long-wavelength infrared systems, zinc selenide can be used, but there are larger reflective losses. In this experiment, the infrared-transmissible windows were made of calcium fluoride. The windows had the best optic natures, but their lower thermal conductivity and higher thermal 


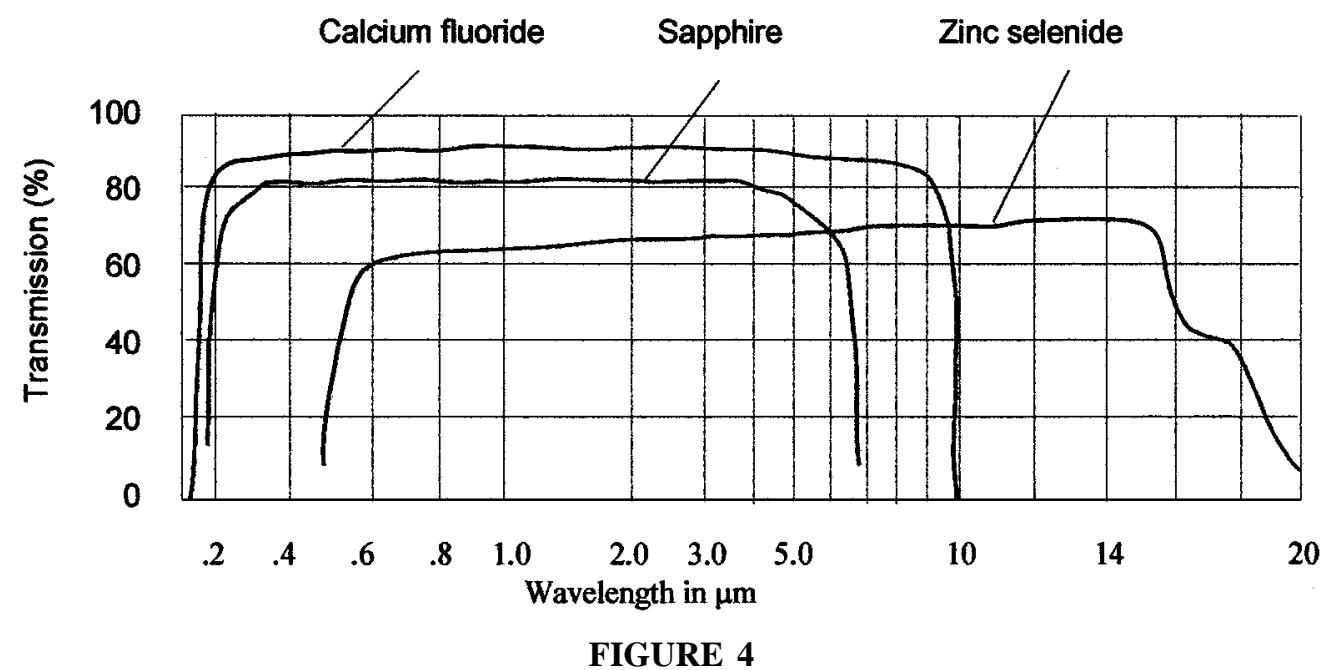

Infrared transmissibility of calcium fluoride, sapphire, and zinc selenide for a window with a thickness of $2 \mathrm{~mm}$.

expansion had to be considered in the design of the window and frame.

\section{Influence of Position and Shape}

Gaussorgues (1989) indicated that metals obey Lambert's law for incidence angles between 0 and 40 degrees and dielectric laws between 0 and 50 degrees. The temperature measurements of objects that obey Lambert's law can yield the same value in all directions of observation. At larger angles, the emissivity received by an infrared detector falls rapidly, and measurement temperature is much lower than the true temperature. In order to obtain an accurate result, the measurable range of the porous circular tube used in the test must be determined by a pilot test.

In this pilot test, the tube was heated in a homogeneous temperature field and the temperature distribution was measured, using the VARIOSCAN 3021 system, from the two angles, as shown in Figure 5. Figure 6 is the thermal image captured from position 1; Figure 7 is the image from position 2. In these images, the temperature distribution on the tube's surface is illustrated by different colors. The white horizontal lines in the two figures indicate the circuits on which temperature distributions are presented below the tube, and the temperatures are illustrated with the same colors and the corresponding height. The vertical white line is the axis of the tube in Figure 6 and is the leading line in Figure 7. Theoretically, the circular tube was at a uniform temperature but, as shown in the figures, the temperature distributions on the circuits were not uniform. Based on the pilot test, the following three conclusions can be drawn:

1. When the infrared scanner was set at position 1 , in the range extending from the tube's axis to 43 degrees, the apparent temperature measurements were not influenced by the position of the infrared scanner and the shape of the substance; in the region of \pm 43 to \pm 62 degrees, apparent temperatures were slightly lower than their true values (by about $2 \%$ ); and at larger angles the apparent temperatures fell rapidly.

2. When the infrared scanner was set at position 2 , the distortion of image led to a lack of theoretical symmetry: temperature distribution was not symmetrical with the leading line of the specimen. In the ranges of 23 and 35 degrees from the leading line, the measurement results of the IRTIT were believed to be accurate.

3. In the application of the IRTIT, the position of the infrared scanner and the shape of the substance are important factors. Although neglected in many published papers, this factor should be considered.

TABLE I

The mechanical natures of calcium fluoride, sapphire, and zinc selenide

\begin{tabular}{lccc}
\hline & Sapphire & Zinc selenide & Calcium fluoride \\
\hline Density & $3.98 \mathrm{~g} / \mathrm{cm}^{3}$ & $5.27 \mathrm{~g} / \mathrm{cm}^{3}$ & $3.179 \mathrm{~g} / \mathrm{cm}^{3}$ \\
Melting point & $2055^{\circ} \mathrm{C}$ & $1500^{\circ} \mathrm{C}$ & $1360^{\circ} \mathrm{C}$ \\
Specific heat & $756 \mathrm{~J} /(\mathrm{kg} \cdot \mathrm{K})$ at $18^{\circ} \mathrm{C}$ & $340 \mathrm{~J} /(\mathrm{kg} \cdot \mathrm{K})$ at $25^{\circ} \mathrm{C}$ & $857 \mathrm{~J} /(\mathrm{kg} \cdot \mathrm{K})$ at $0^{\circ} \mathrm{C}$ \\
Thermal conductivity & $24 \mathrm{~W} /(\mathrm{m} \cdot \mathrm{K})$ at $18^{\circ} \mathrm{C}$ & $18 \mathrm{~W} /(\mathrm{m} \cdot \mathrm{K})$ at $25^{\circ} \mathrm{C}$ & $1.037 \mathrm{~W} /(\mathrm{m} \cdot \mathrm{K})$ at $0^{\circ} \mathrm{C}$ \\
Thermal expansion & $6.5 \times 10^{-6} / \mathrm{K}$ at $0^{\circ} \mathrm{C}$ & $7.1 \times 10^{-6} / \mathrm{K} \mathrm{at} 0^{\circ} \mathrm{C}$ & $18.9 \times 10^{-6} / \mathrm{K} \mathrm{at} 20^{\circ} \mathrm{C}$ \\
Young's modulus & $345 \times 10^{3} \mathrm{~N} / \mathrm{mm}^{2}$ & $679 \times 10^{3} \mathrm{~N} / \mathrm{mm}^{2}$ & $76 \times 10^{3} \mathrm{~N} / \mathrm{mm}^{2}$ \\
\hline
\end{tabular}




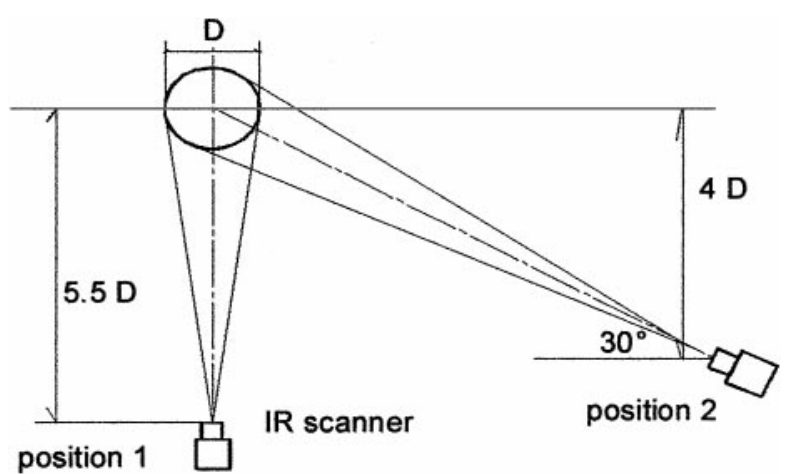

FIGURE 5

Position of infrared scanner for measurement.

In the further experiments, temperature measurements were carried out through the three windows. The corresponding viewing angles were 0 and \pm 60 degrees. Thus this pilot test could provide a reference for the additional experiments by determining the region for the calculation of the average cooling effect and of the position of calibration of the thermocouple.

\section{Stability of Measurement}

A test of the stability of IRTIT measurement was conducted in the wind tunnel. The temperature of a pixel was traced through 40 frames of thermal images that were captured using

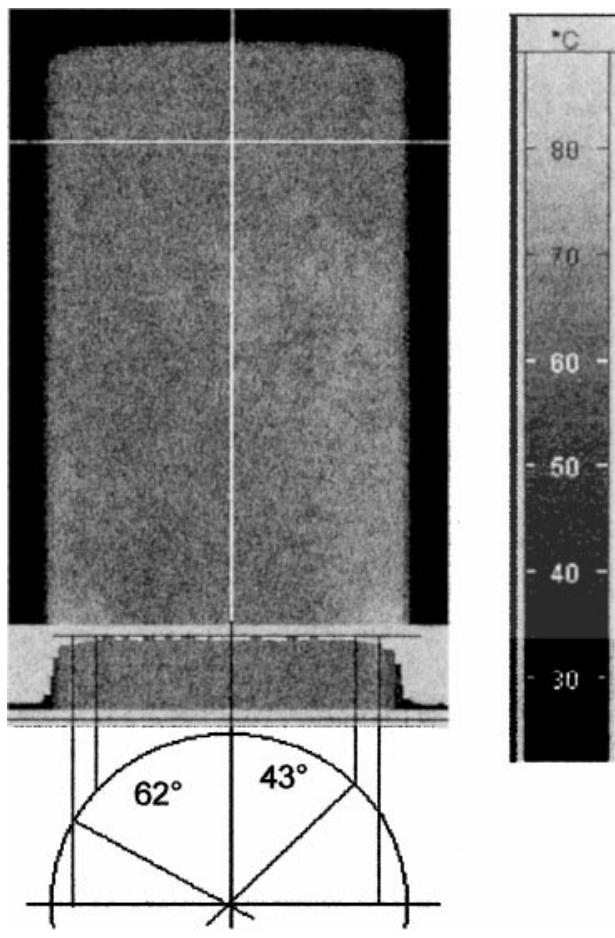

FIGURE 6

Identification of an exact measurement range from position 1, as shown in Figure 5.

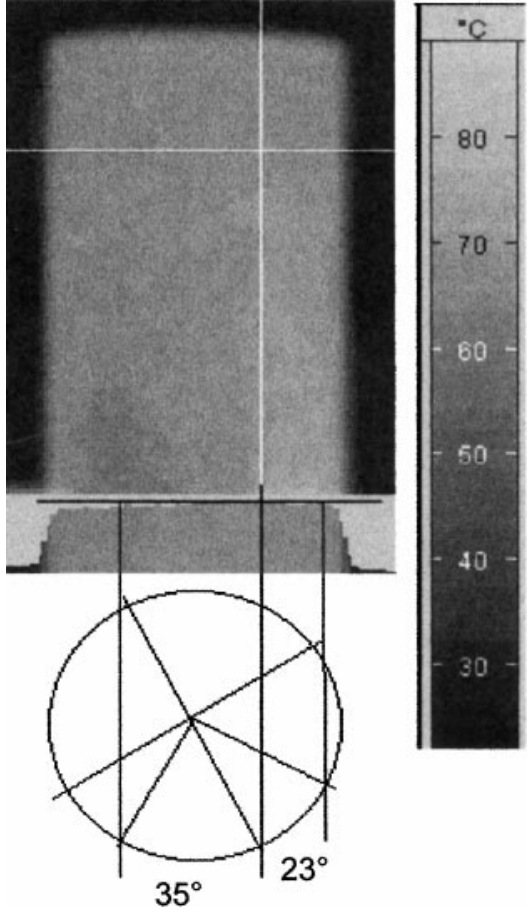

FIGURE 7

Identification of an exact measurement range from position 2, as shown in Figure 5.

VARIOSCAN 3021 under a constant condition. Thus, the stability of measurement data was independent of the position, the surrounding, and the infrared window. Figure 8 shows the probable density distribution of the temperatures traced. This probability could be expressed as a normal distribution

$$
P=\frac{1}{\sqrt{2 \pi}} e^{-\frac{(T-a)^{2}}{2 \sigma^{2}}}
$$

where $T$ is the temperature, $P$ is the probability density, $a$ is the mean temperature, and $\sigma$ is the corresponding deviation of this measurement event. Equation (1) was written as:

$$
P_{e}=A_{1} T^{2}+A_{2} T+A_{3}
$$

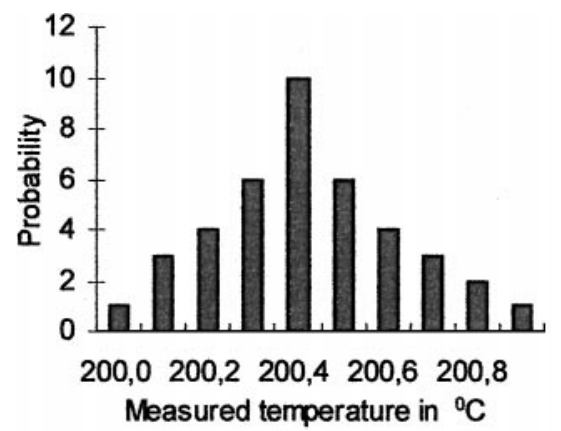

FIGURE 8

Stability of measurement data. 
where $P_{e}$ is logarithm $P . A_{1}, A_{2}$, and $A_{3}$ were fitted by using the least squares root. The averaged temperature and the corresponding deviation of this measurement event were $200.45^{\circ} \mathrm{C}$ and $0.2^{\circ} \mathrm{C}$, respectively.

The infrared measurement was stable enough for this experimental investigation. The stability depended on the performance of the infrared measurement system. The measurement deviation of the AGA 782 system was larger than that of VARIOSCAN 3021 in the same condition because the VARIOSCAN 3021 system had high thermal and geometric resolution.

The means of averaging images is available to obtain a more stable result. In Part II of this article, all measurement results were acquired in 20 frames of instantaneous thermal images.

\section{The Effect of Emissivity on Thermography}

A black body can give an excellent measurement, but the result will be poor when the emissivity is low, and the infrared measurement is impossible for the highly reflecting materials whose self-emission is close to nil. This is why the measured surfaces were artificially blackened in the references mentioned above. In this test, the artificial coating method was not used, and the infrared measurement was conducted directly on a gray body surface. If the emissivity of the gray body surface is known and is large enough to be detected by an infrared measurement system, the surface can be directly measured.

In order to evaluate the emissivity, a fine thermocouple with a diameter of $0.5 \mathrm{~mm}$ was installed into the wall of the tube, as shown in Figure 9. The thermocouple was movable and could be pushed forward as close as possible to the outside of the specimen. The infrared scanner was placed at position 1, as shown in Figure 5, where the measurement data of the IRTIT were not influenced by the shape of the material. The surface emissivity

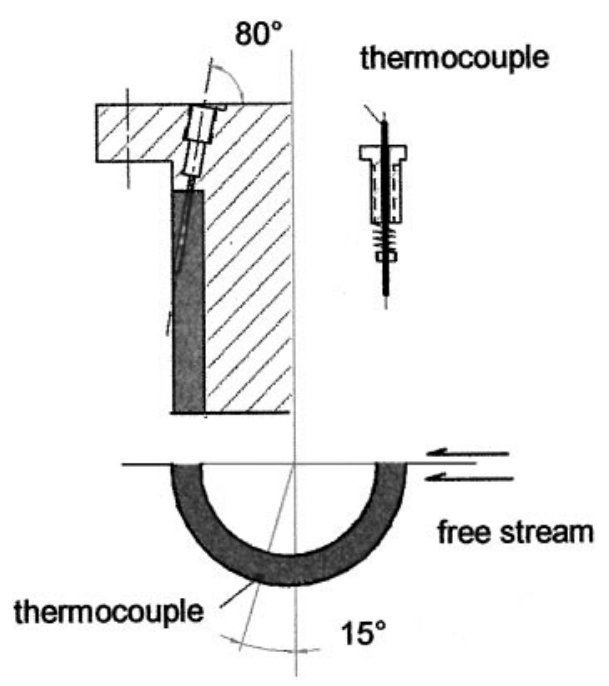

FIGURE 9

Position of thermocouple. was rectified so that the temperature measured using the infrared method was identical to that using the thermocouple at the same point. This final value was seen as being the emissivity of the porous surface; it ranged from 0.91 to 0.94 and was sufficient for the infrared measurement without coating.

\section{Influence of Ambient Condition}

It is relatively difficult to describe the influence of ambient radiation on a circular tube with a simple formula because at each point on the circular surface, the influence level of the ambient radiation is different. Thus, in many studies the inside and the outside of test sections were coated with a flat black paint to reduce reflected thermal energy and to minimize the straying of thermal energy into the detector. However, in this experiment, the coating process was eliminated; an important argument for this decision was that the cooling effect defined and used in this test is a different concept.

Assuming that the ambient condition in the cooling process was kept constant, the influence of the ambient condition on the cooling effect could be negligible. The error due to this assumption will be discussed later.

\section{CALIBRATION OF MEASUREMENT DATA}

Thermography is a technique of recording phenomena associated with the spatial distribution of heat on an object. Thermographic equipment can transform an infrared image into a visible image that can be expressed as a gray-scale level. In this experiment, the image was transmitted by a video signal, which can be recorded in the form of an analogue voltage or a current and must be processed to yield a temperature distribution over the scene in an exponential relationship:

$$
I=a /\left\{\exp \left[b /\left(t_{c n}+273\right)\right]-1\right\}
$$

where $t_{c n}$ is the centigrade temperature of the black body image, and $a$ and $b$ are two constants that are dependent upon the objective and on the aperture and spectral filter employed. The influence factors of the infrared transmissible window, the shape, and the surface emissivity were not considered in Equation (3), so it was necessary to calibrate the data obtained by the infrared measurement.

The thermal images of the two infrared systems can provide complete information regarding temperature and the corresponding pixel number, but because the data block file AGA 782 system outputs gray-scale level $G$, and the VARIOSCAN 3021 system produces direct temperature $T$ (Equation 4), the measurement data were calibrated using different methods for each of the two systems.

The calibration tests were carried out in the hot-gas wind tunnel, so this calibration included surface emissivity and window transmission, but not the influence of ambience and stability. The relative positions of the infrared scanner and the specimen were the same as position 1 and position 2 in Figure 5. 


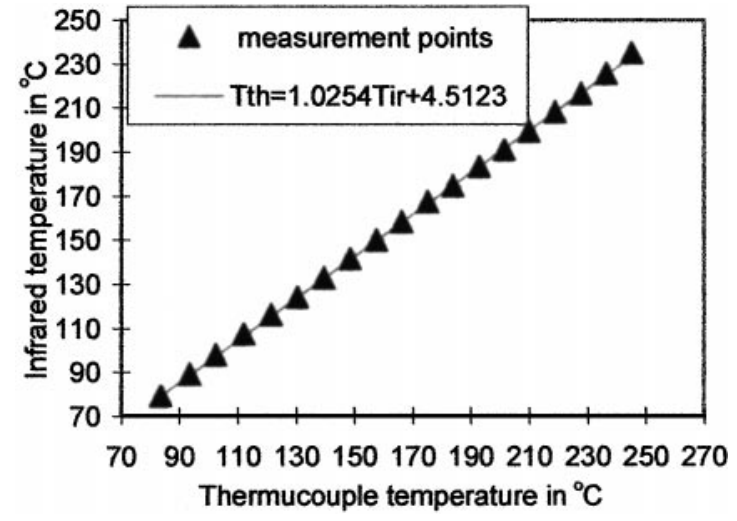

FIGURE 10

Relationship between gray-scale level and temperature.

1. The input value of the emissivity was adjusted to rectify the output of the infrared system until the output was identical to the temperature measured by thermocouple at the same point. This calibration method is usable for both infrared measurement systems.

2. The relationship of the gray-scale level $G$ and the true temperature $T$ was established. Steady-state calibration data were acquired from the mid window with a $0^{\circ}$ viewing angle under various free-stream temperatures. The thermal level, thermal range, and aperture in this test were 136, 200, and 2.5, respectively. As shown in Figure 10, the relationship seems to be nearly linear. Stetter and colleagues (2000) suggested using linear relation

$$
T=a G+b
$$

to fit this relation, where $a$ and $b$ could be calculated using the least square root. The error resulting from this approach was less than $\pm 3^{\circ} \mathrm{C}$ in this test.

3. The relationship between the temperature obtained using the infrared system Tir and the thermocouple Tth was established. Figure 11 illustrates the measurement point relationship of Tir and Tth acquired from the mid window. If the data

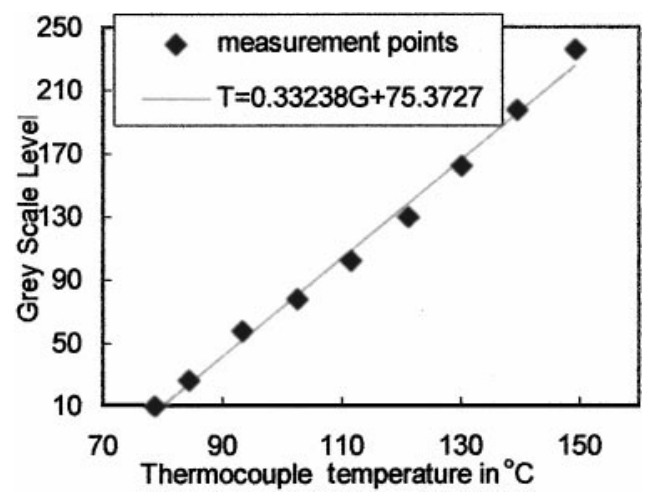

FIGURE 11

Relationship between infrared measurement and thermocouple. points were substituted for a linear relationship, the maximal error in this approach was less than $\pm 2^{\circ} \mathrm{C}$. As shown in Figure 11, Tir is always lower than Tth, and the difference between them increases with temperature.

From different viewing angles, these calibration lines are different. Thus, the same experiments were carried out through the other windows of the wind tunnel.

\section{COOLING EFFECT}

In most studies of film cooling, film effect is characterized with an adiabatic wall temperature and a heat-transfer coefficient on the hot flux side. However, it is impossible to create an adiabatic wall condition on a metal surface, so in the references associated with the application of the IRTIT, the cooling effect

$$
\eta=\left(T_{\infty}-T_{c w}\right) /\left(T_{\infty}-T_{c}\right)
$$

was usually used. $T_{\infty}, T_{c w}$, and $T_{c}$ are the temperatures of the free stream, the cooled wall, and the coolant, respectively. This definition is suitable for evaluating the cooling effect of a flatplate specimen, but in this test a circular tube was used as the specimen. Thus, the following two concepts were defined and used to describe the local and average cooling effect on the circular specimen's surface:

$$
\begin{array}{r}
\eta_{\mathrm{loc}}=\left(T_{i w}-T_{c w}\right) /\left(T_{\infty}-T_{c}\right) \\
\eta_{\mathrm{avg}}=\frac{\int_{A}\left(T_{i w}-T_{c w}\right) d A}{\left(T_{\infty}-T_{c}\right) A}
\end{array}
$$

where $T_{i w}, T_{c w}, T_{c}$, and $T_{\infty}$ are the initial wall temperature when no coolant had been injected and the temperatures of the cooled wall, the coolant, and the free stream, respectively, and $A$ is the area. The $\eta_{\text {loc }}$ and $\eta_{\text {avg }}$ differ from the $\eta$ in Equation (5) because in the uncooled case, $\eta_{\text {loc }}$ and $\eta_{\text {avg }}$ are zero, but the latter is not zero.

In the cooling process, the ambient influence on $T_{i w}$ and $T_{c w}$ could be seen to be identical. In the temperature drop from $T_{i w}$ to $T_{c w}$, this influence could be neglected, thus the surface coating on the test section could be eliminated in this test. The error resulting from this assumption could be examined by means of the following test.

The examination was carried out at a mainstream temperature of $240^{\circ} \mathrm{C}$. Figure 12 shows two thermal images that were captured using the function of the on-line temperature difference of the VARIOSCAN 3021 system. The same reference background was recorded for the two measurements when no coolant had been injected. The top image illustrates the difference between two random measurements under the same conditions, namely, without coolant injection. The bottom image shows the difference between the cases-without and with coolant injection from the pores in the trailing region. In the two images, 


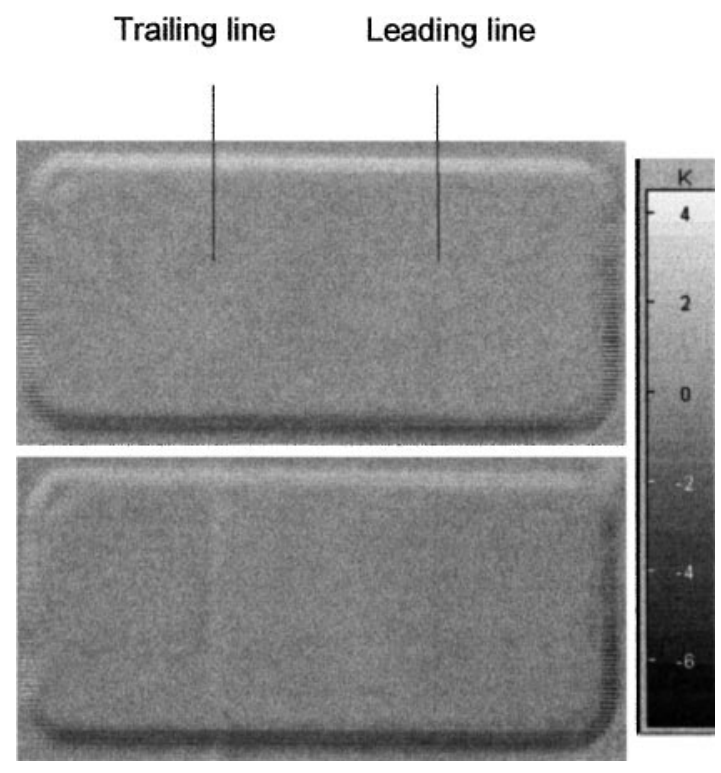

FIGURE 12

Examination of effect of ambience on tube's surface through measurement of temperature differences.

the largest temperature differences occurred on the window's frame. The unstable effect of the edge radiation on the frame caused the largest temperature differences. On the tube's surface, in the uncooled case, the temperature differences were less than $\pm 1 \mathrm{~K}$; when coolant was injected into the trailing region chamber at a small rate, it could be found that in the region that was not cooled, the temperature differences were less than $\pm 1 \mathrm{~K}$. This examination demonstrated that the relative error due to the ambient condition approach was less than $\pm 1 \%$ in this test.

\section{SUMMARY AND DISCUSSION}

The IRTIT is the most effective method for evaluating the performance of porous transpiration cooling. After experiments and analysis, it can be said that in a measurement event, the true temperature is influenced by the transmission of infrared material, the position of the infrared scanner, the surface emissivity of porous material, the stability of the infrared system, and the ambient condition. Thus, the relationship between the temperature measured, $T_{m}$, using the IRTIT and the true temperature, $T_{t}$, may be expressed as

$$
T_{m}=f_{w} f_{p} f_{e} T_{t} \pm T_{s}^{\prime}+T_{a}
$$

where $f_{w}, f_{p}$, and $f_{e}$ are the influence factors of the infrared window, the infrared scanner position, and the surface emissivity, respectively; $T_{s}^{\prime}$ and $T_{a}$ are the fluctuation of measurement resulting from the stability of the infrared system and the additional temperature of the ambient thermal radiation.

The experiment indicates that the stability problem of infrared measurement may be improved by averaging images. Through this process, the fluctuation is reduced so that it can be neglected in the averaged measurement:

$$
\bar{T}_{m}=f_{w} f_{p} f_{e} T_{t}+T_{a}
$$

The study suggests that the local and averaging cooling effect defined according to Equations (6) and (7) can be used to evaluate the transpiration cooling effect of circular specimens. The additional ambient term may be dropped from the expression of temperature drop:

$$
T_{t 1}-T_{t 2}=\frac{\bar{T}_{m 1}-\bar{T}_{m 2}}{f_{w} f_{p} f_{e}}
$$

The three factors, $f_{w}, f_{p}$, and $f_{e}$, are always less than or equal to 1. That is why the temperature measured by the IRTIT is always lower than the temperature measured by the thermocouple, and the difference between them increases with temperature.

The influence of the position and shape on the measurement data has to be considered in experiments involving circular specimens and turbine blades. The measurable range of circular specimens or turbine blades should be identified before testing. In the established range, the influence factor of position and shape may be seen as 1 .

The influence factor of the infrared transmissible window is always less than 1 , and the influence levels of this factor are different for the two infrared measurement systems.

If the measured object is an ideal black body, the emissivity influence factor may be 1 or less. The apparent temperature of a porous tube seen as a gray body can be directly measured using the IRTIT. In order to obtain an accurate cooling effect, the averaged temperature drop has to be calibrated through the comparison of data measured using an established measurement technique. The total influence of these three factors on the temperature drop is considered through this comparison calibration.

The IRTIT is the most effective means to measure and evaluate transpiration cooling performance. A satisfying measurement accuracy can be achieved when the IRTIT is applied correctly.

\section{REFERENCES}

Bonnice, M. A., and L'Ecuyer, M. R. 1983. Stagnation region gas cooling: effects of dimensionless coolant temperature. NASA CR-168197.

Boyle, R. J., Spuckler, C. M., Lucci, B. L., and Caperchioli, W. P. 2001. Infrared low-temperature turbine vane rough surface heat transfer measurement. ASME Journal of Turbomachinery 123:168-177.

Ekkad, S. V., Zapata, D., and Han, J.-C. 1997a. Heat transfer coefficients over a flat surface with air and $\mathrm{CO}_{2}$ injection through compound angle holes using a transient liquid crystal image method. ASME Journal of Turbomachinery 119:580-586.

Ekkad, S. V., Zapata, D., and Han, J.-C. 1997b. Film effectiveness over a flat surface with air and $\mathrm{CO}_{2}$ injection through compound angle holes using a transient liquid crystal image method. ASME Journal of Turbomachinery 119:587-593.

Ekkad, S. V., Han, J. C., and Du, H. 1998. Detailed film cooling measurements on a cylindrical leading edge model: effect of free-stream 
turbulence and coolant density. ASME Journal of Turbomachinery 120:799-807.

Friedrichs, S., Hodson, H. P., and Dawes, W. N. 1997. Aerodynamic aspects of endwall film cooling. ASME Journal of Turbomachinery 119:786-793.

Gaussorgues, G. 1989. Infrared Thermography. Cambridge: Chapman \& Hall, London University Press.

Karni, J., and Goldstein, R. J. 1990. Surface injection effect on mass transfer from a cylinder in crossflow: a simulation of film cooling in the leading edge region of a turbine blade. ASME Journal of Turbomachinery 112:418-427.

Martiny, M., Schulz, A., and Wittig, S. 1995. Full-coverage film cooling investigations: adiabatic wall temperature and flow visualization. ASME Paper No. 95-WA/HT-4.

Mehendale, A. B., and Han, J. C. 1992. Influence of high mainstream turbulence on leading edge film cooling heat transfer. ASME Journal of Turbomachinery 114:707-715.

Nirmalan, N. V., Weaver, J. A., and Hylton L. D. 1998. An experimental study of turbine vane heat transfer with water-air cooling. ASME Journal of Turbomachinery 120:50-61.
Sargent, S. R., Hedlund, C. R., and Ligrani, P. M. 1998. An infrared thermography imaging system for convective heat transfer measurements in complex flows. Measurement Science and Technique 9:1974-1981.

Scherer, V., Wittig, S., Morad, K., and Mikhael, N. 1991. Jets in a crossflow: effects of hole spacing to diameter ratio on the spatial distribution of heat transfer. ASME Paper No. 91-GT-356.

Schmidt, D. L., Sen, B., and Bogard, D. G. 1996. Film cooling compound angle holes: adiabatic effectiveness. ASME Journal of Turbomachinery 118:807-813.

Sweeney, P. C., and Rhodes, J. F. 2000. An infrared technique for evaluating turbine airfoil cooling designs. ASME Journal of Turbomachinery 122:170-177.

Stetter, H., Wang, J. H., and Messner, J. 2000, March. An experimental investigation of transpiration cooling. Part I: feasibility test and performance estimation 777-785. Proceedings of the 8th ISROMAC, vol. II. Honolulu, HI.

Wittig, S., Schulz, A., Gritsch, M., and Thole K. A. 1996. Transonic film-cooling investigations: effects of hole shapes and orientations. ASME Paper No. 96-GT-222. 

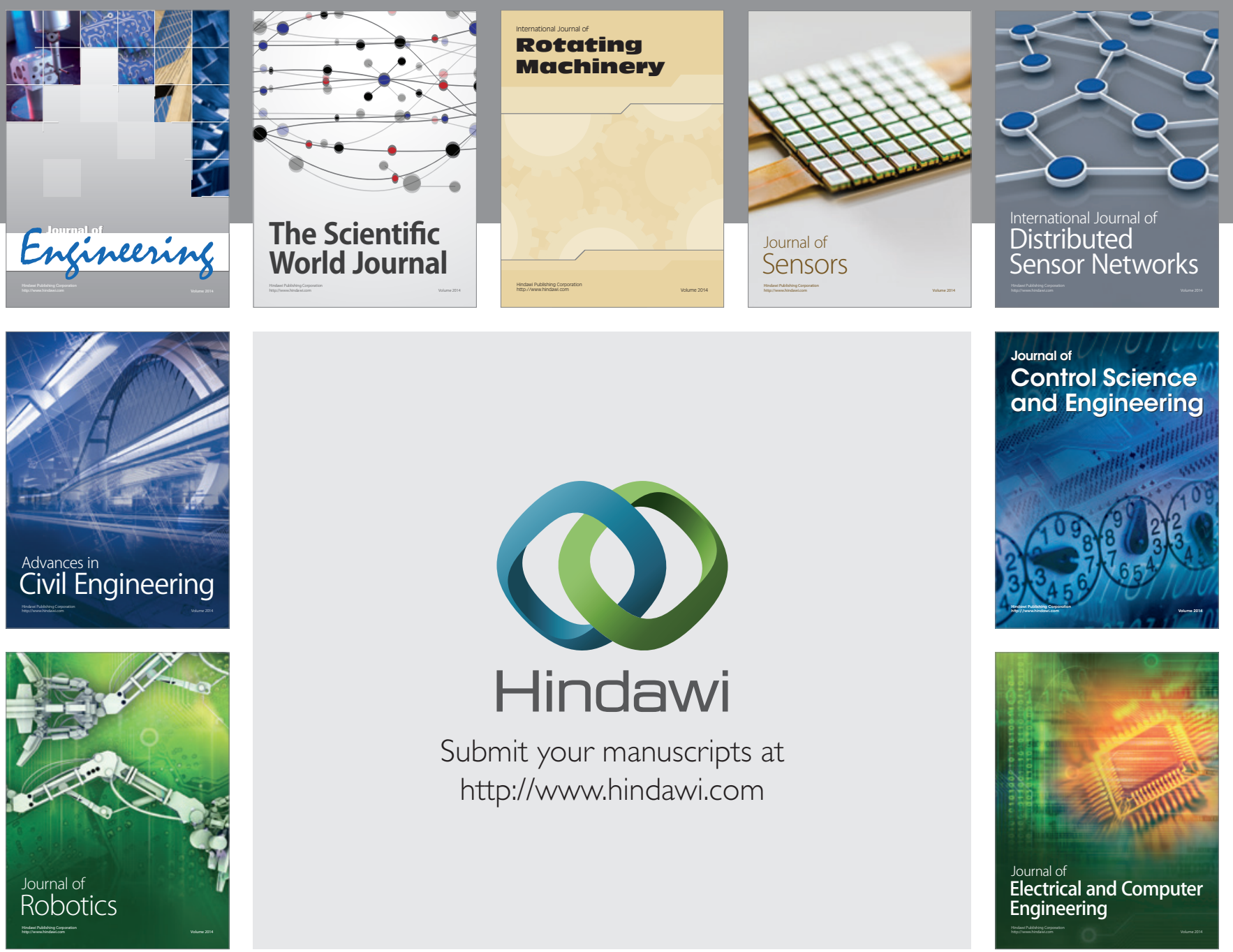

Submit your manuscripts at

http://www.hindawi.com
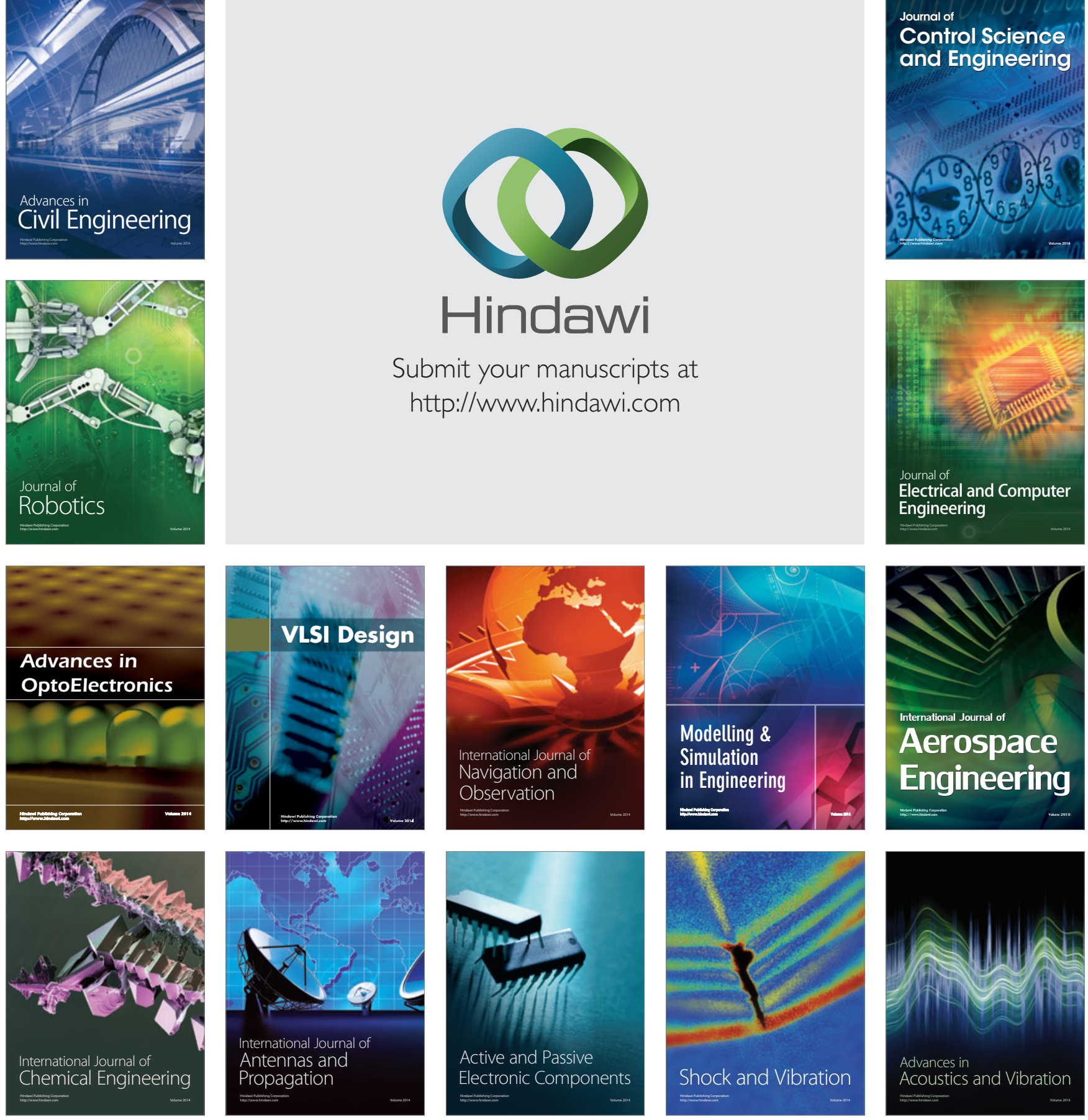